\title{
Estudos sobre o objeto da Ciência da Informação: da constituição de um grupo de pesquisa a um de seus resultados
}

Studies on the subject of information science: the creation of a research group to one of your results

Cristina Dotta Ortega

Doutora em Ciência da Informação pela ECA/USP. Professora Adjunta da Escola de Ciência da Informação da Universidade Federal de Minas Gerais - ECI/UFMG.

E-mail: ortega@eci.ufmg.br

\section{Resumo}

Trata da constituição do grupo ibero-americano de pesquisa sobre Ciência da Informação, depois reconfigurado na perspectiva de uma rede com a entrada de mais pesquisadores brasileiros. A seguir, são apresentados alguns conceitos básicos e as relações entre eles como parte da proposta explicativa de objeto da Ciência da Informação, que foi um dos produtos individuais dos debates realizados no âmbito do grupo.

Palavras-chave: Ciência da Informação; Grupos de Pesquisa

\begin{abstract}
It is about the constitution of the Ibero-American group of research on Information Science, which was afterwards reconfigured within the perspective of a net with the entry of more Brazilian researchers. Then we present some basic concepts and the relations among them as part of the explanatory proposal of the object of Information Science, which was one of the individual products from the debates carried out within the group.
\end{abstract}

Keywords: Information Science; Group of research

Este texto se inscreve no engendramento de dois fatos em curso na pesquisa em Ciência da Informação: o questionamento sobre os avanços efetivos proporcionados pela discussão em torno de seu objeto e as relações acadêmicas fortemente construídas entre pesquisadores ibero-americanos, incluindo mexicanos.

O grupo de pesquisa em questão foi decorrência do Seminario Hispano-Mexicano ocorrido em abril de 2010, no então Centro Universitario de Investigaciones Bibliotecológicas, da Universidad Nacional Autónoma de México (CUIB/UNAM), atual Instituto de Investigaciones Bibliotecológicas y de la Información (IIBI). Sob a denominação de Grupo Iberoamericano de trabajo acerca de la naturaleza de la Bibliotecologíal Documentación/ Ciencia de la Información, foi explicitada a preocupação com a falta de visibilidade da área e sua repercussão na formação de alunos, na escolha de linhas de pesquisa e nas perspectivas do mercado de trabalho. O Grupo foi constituído naquele momento 
levando-se em conta a reflexão realizada por pesquisadores deste centro mexicano de pesquisa e da Sección Departamental de Biblioteconomía y Documentación, da Facultad de Ciencias de la Información (UCM), da Espanha, a partir do que, outros pesquisadores iberoamericanos envolvidos com o tema deveriam ser incorporados.

Com o objetivo de viabilizar as atividades do grupo já ampliado, o professor do IIBI/UNAM Miguel Ángel Rendón Rojas produziu e obteve recursos para o projeto de pesquisa Un análisis teórico-epistemológico de la Bibliotecología y Estudios de la Información. Unidad en la diversidad: Bibliotecología, Documentación y Ciencia de la Información. Sob sua coordenação, foi realizado o Seminario Especializado sobre Epistemología de la Bibliotecología y Estudios de la Información, como primeira atividade do Grupo, na UNAM em outubro de 2011, juntamente com outros seminários temáticos e antecedendo o XXIX Coloquio de Investigación Bibliotecológica daquela universidade. Os membros presentes foram: o coordenador Miguel Rendón Rojas; José López Yepes, da Universidad Complutense de Madrid, Espanha; Francys Delgado e Johann Pirela, da Universidad de Zulia, Maracaibo, Venezuela; Eduardo Mancipe Flechas, da Universidad de La Salle, Bogotá, Colômbia; Nathalia Quintero de Castro, da Universidad de Antioquia, Medellín, Colômbia; e Cristina Dotta Ortega, da Universidade Federal de Minas Gerais, Belo Horizonte, Brasil.

Nesta reunião, cada pesquisador apresentou sua própria elaboração sobre o objeto da área, a partir do que, discussões foram feitas sobre divergências e convergências e os argumentos que as sustentam, deflagrando ao menos duas evidências: diversos consensos e empatia para produção acadêmica contínua.

As apresentações iniciais dos pesquisadores foram repensadas segundo as discussões realizadas naquele momento e, posteriormente, à distância e em outros encontros, demonstrando a produtiva troca de ideias. Este material comporá livro na forma de capítulos. As reflexões que seguem representam parte do texto por mim elaborado a partir de proposta inicial que foi retomada em função deste enriquecedor encontro de pessoas e ideias.

Com a vinda do professor Miguel Rendón Rojas a universidades brasileiras, o Programa de Pós-Graduação de Ciência da Informação da USP organizou o I Colóquio Internacional de Ciência da Informação, em abril de 2012. Sob o tema Epistemologia e Objetos de Estudo, o evento contou com pesquisadores de diversos estados do sudeste brasileiro que exerceram a função de debatedores ou interventores. Como pauta do evento, foi 
discutida a participação brasileira no Grupo, criando-se uma rede de pesquisadores, na forma de um grande braço do Grupo inicial.

Nosso trabalho foi desenvolvido sob a compreensão de que é pertinente explorar o objeto da Ciência da Informação balizado pela identificação de seu objetivo ou finalidade. Esta posição está amparada pela ideia de que uma ciência social aplicada realiza-se na perspectiva de problemas ou questões que correspondem a necessidades de pessoas em seus contextos sociais e atividades relacionadas. Sendo assim, essa ciência não teria explicação suficiente na eleição de um objeto, no sentido clássico de ciência, apresentando antes objeto teórico que se constitui pela articulação de objetos empíricos, como pessoas, processos e produtos, cuja orientação é essencialmente pragmática.

Para além de necessidades de informação objetivamente formuladas como demandas, trata-se das necessidades humanas de informação, portanto, inerentes a todo ser humano e relativas a aspectos de ordem científica, educacional, utilitária, de entretenimento, estética, profissional, outras. Para a identificação do objetivo ou finalidade da área como percurso para constituição de seu objeto, apontamos como fenômeno propulsor as necessidades de informação que, abordadas quanto aos modos e meios de satisfazê-las, e as motivações e implicações dos mesmos, compõem seus aspectos nucleares.

Ao considerar a centralidade dos modos e meios estudados e propostos pela área, deflagramos como seu objeto a mediação da informação, no sentido de mediação entre objetos e pessoas abordados, respectivamente, como documentos e usuários. Dito de outro modo, temos uma mediação entre objetos potencialmente informativos e pessoas potencialmente usuárias da informação.

A mediação tem como alvo a comunicação - que se dá via informação - entre a representação do objeto e o sujeito que a interpreta. Segundo Lara (1993, p. 27), a comunicação se efetiva no momento da apropriação.

A apropriação da informação ocorre quando há apreensão da informação pelo usuário, cujo protagonismo permite a tomada de decisão ou a construção de conhecimento, em processo que é influenciado pelos modos de oferta dos conteúdos e pelas características dos mecanismos de acesso (segundo elaboramos a partir de PERROTI ; PIERUCCINI, 2007). Embora fazendo uso do termo apropriação cultural no contexto de ações educacionais e informacionais, interessa-nos a conceituação dos autores segundo a qual a apropriação 
implica atuação e afirmação dos sujeitos nas dinâmicas de negociação de significados, ou seja, trata-se de transação de significados que diferencia e constitui os negociadores como sujeitos da cultura, protagonistas, cidadãos (p. 74). De outro modo, nossa opção pelo termo apropriação da informação refere-se à condição de que operamos com informação e de que a mesma constitui-se enquanto linguagem, a qual é elemento da cultura, no sentido de que cultura e linguagem não podem ser suficientemente compreendidas na ausência uma da outra.

Retomamos a frase explicativa de que a área se ocupa de organização e recuperação da informação, já que a afirmação leva à ideia de nivelamento conceitual entre os dois termos e de relação causal e direta do primeiro para o segundo. Organização da informação é meio para a recuperação, do que decorre que meios e fins não podem ser submetidos ao mesmo tipo de noção. Recuperação da informação tem sido reduzida a um conjunto de operações mecânicas de busca por registros de bases de dados cuja informatividade não está em questão, sendo entendida antes como procedimento unidirecional e neutro que como objetivo. Não à toa, Marteleto trata da incompletude dos processos de produção e apropriação da informação, uma vez que a emissão é diferente da recepção, ou seja, não há colagem, encaixe ou coincidência entre os pólos da emissão/produção e da recepção/consumo (MARTELETO, 2007, p. 20).

Revisitando o conceito - tão caro à área -, temos que recuperação da informação implica comunicação. Para Meadow (1992), quando se fala em recuperação da informação, o conceito implicitamente em questão é seletividade. Encontrar informação não é o mesmo que recuperar informação, pois este processo envolve seleção.

Como o objeto teórico da área foi proposto quanto à sua finalidade, tratamos dos objetos empíricos com o fim de fornecer forma e conteúdo ao primeiro. Citados abaixo, os objetos empíricos configuram-se, de modo interdependente, como objetos, pessoas, processos, produtos e ações.

Deste modo, documentos e usuários são considerados em certos contextos institucionais, a partir do que são construídos sistemas documentários segundo as tecnologias de cada tempo, e estratégias gerenciais para racionalização e otimização de recursos e processos, via procedimentos de organização da informação e de armazenamento e preservação de documentos, cujo uso é potencializado por serviços de informação, exposições e ações educativas e culturais. 
A articulação entre estes objetos empíricos permite entender e conformar o objeto da área que se relaciona, portanto, à intervenção realizada entre a produção e o uso de informação, por meio da elaboração de registros ou inscrições, e demais atividades que possibilitam a permanência destes registros e o acesso e usos posteriores. Está em questão um fazer informativo que visa o uso qualificado da informação, cuja orientação é construída segundo interesses institucionais e seus públicos, mas não subordinada acriticamente a eles.

Considerando que as atividades da área tem início com a identificação de públicos e documentos, e envolvem metodologias e instrumentos de organização da informação, assim como os serviços de informação e as ações educativas e culturais, temos de fato instrumentos e ações de mediação da informação. Deste modo, a mediação da informação não ocorre apenas no momento em que o usuário aciona o sistema ou quando se dá o serviço de referência, mas quanto ao conjunto de propostas de significação que constituem o sistema e que são realizadas a partir dele, e demais atividades sistêmicas e contextualizadas visando apropriação da informação pelo usuário.

A apropriação da informação se efetiva sob a articulação de duas perspectivas da atividade documentária: propostas de significação oferecidas ao usuário e ausência de qualquer tipo de controle sobre a interpretação a ser realizada pelo usuário. Sendo a interpretação influenciada ou orientada pelas propostas de significação, estudos da primeira estariam comprometidos se realizados sem a consideração das segundas, enquanto variável que particulariza e explica a área.

A apropriação da informação ressalta a perspectiva educacional da área para além de ambientes em que a mesma é privilegiada como no caso da biblioteca escolar. Embora não haja garantia de que a mediação conduza à apropriação da informação, a existência da primeira, em sua relação com a segunda, indica seus modos de realização no contexto da área. Ao prescindir dos processos e instrumentos de mediação de informação, ou considerá-los desejáveis mas não necessários ou intrínsecos, está colocada a área da Educação, que se explica por sua própria função social e meios para contemplá-la.

A noção de informação de que se ocupa a área vincula-se à produção de mensagens sobre objetos selecionados, portanto, ao conjunto das teorias, metodologias e instrumentos que dão forma a certos conteúdos, formas essas elaboradas como orientandoras da produção de novos conhecimentos ou da tomada de decisões por pessoas no contexto dos seus grupos sociais e atividades relacionadas. 
Sintetizando, formulamos como objeto da área a mediação da informação, noção que é constituída a partir do seu objetivo. Este objetivo contempla necessidades de informação, frente às quais se promove recuperação da informação, processo de comunicação que somente se efetiva quando há apropriação da informação pelos usuários.

Comentamos ainda que a celeuma que marca os debates sobre Ciência da Informação e que se constitui pela percepção de uma crise de identidade baseia-se em geral em afirmação repetida mas não historicizada e conceituada, demonstrando antes um modo de expressar as dificuldades vividas pelos próprios pesquisadores. Embora seja necessário reconhecer a existência de problemas estruturais, entendemos que a ideia de crise de identidade não se sustenta se considerarmos seus fundamentos teóricos e metodológicos e suas melhores práticas.

Considerando o estágio da área e sua constituição histórica particular, seu objeto não pode ser descrito ligeiramente, sob pena de apresentar simplificações e desvios que comprometeriam a empreitada. Parte desta atividade envolve a discriminação entre aspectos contingenciais e essenciais relacionados à exploração de conceitos fundamentais que sustentam objeto teórico sob a articulação de objetos empíricos.

\section{Referências}

LARA, M. L. G. Representação documentária: em jogo a significação. 1993. Dissertação (Mestrado) - Escola de Comunicações e Artes, Universidade de São Paulo, 1993.

MARTELETO, R. M. O lugar da cultura no campo de estudos da informação: cenários prospectivos. In: LARA, M. L. G. de ; FUJINO, A.; NORONHA, D. P. (Orgs.). Informação e contemporaneidade: perspectivas. Recife: Néctar, 2007. p. 47-98. Disponível em: $<$ http://www.pos.eca.usp.br/sites/default/files/file/cienciaInformacao/informacaoContemporan iedade.pdf $>$. Acesso em: 01 jun. 2012.

MEADOW, C. T. Text information retrieval systems. San Diego: Academic Press, 1992. p. 2-19.

PERROTTI, E. ; PIERUCCINI, I. Infoeducação: saberes e fazeres da contemporaneidade. In: LARA, M. L. G. de ; FUJINO, A.; NORONHA, D. P. (Orgs.). Informação e contemporaneidade: perspectivas. Recife: Néctar, 2007. p. 47-98. Disponível em: $<$ http://www.pos.eca.usp.br/sites/default/files/file/cienciaInformacao/informacaoContemporan iedade.pdf $>$. Acesso em: 01 jun. 2012. 